\title{
"AINDA APROVEITÁVEL": UMA LEITURA DESCONSTRUTIVISTA
}

Sigrid Renaux*

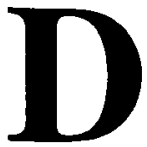

entro do conto moderno existem duas vertentes: a épica e a lírica. A primeira, constituída pela maioria das narrativas, é marcada pela ação externa desenvolvida silogisticamente através de personagens que levam adiante um enredo, culminando num final decisivo que conduz a uma visão interior e universal. A outra se concentra em mudanças internas, sentimentos e estados de espírito, desvendando o valor latente de um episódio, com final aberto, usando padrōes estruturais que dependem da forma da própria emoção e expressa através da linguagem figurada e evocativa de um poema. ${ }^{1}$ $\mathrm{Na}$ criação da narrativa lírica norte-americana, John Updike se coloca ao lado de grandes nomes como Turgenev, Chekov, Mansfield, Lawrence e Woolf, entre outros e seu conto "Still of Some Use" destaca-se precisamente pelo fato de transmitir, em linguagem aparentemente trivial, emoções que também são quase

* Universidade Federal do Paraná

1 BALDESHWILER, E. "The Lyric Short Story: The Sketch of a History". In: Short Story Theories. Ed. Charles E. May. Ohio University Press, 1976. p.202. 
as usuais que vinculamos a objetos de nossa vida diária e que podemos ter tido ou vir a ter. Pois neste conto - no qual um pai divorciado, a ex-mulher e os dois filhos estão cumprindo o ritual de retirar do sótão objetos de sua antiga casa, agora à venda - pequenos gestos e opiniōes são transmitidos com grande fidelidade aos ritmos da fala e nos pöem em contato com correntes de ressentimento, dor e saudade íntima que as personagens prefeririam suprimir ou das quais imaginavam estar livres. $E$ os espaços e objetos mais comuns, minuciosamente catalogados, estão repletos de significados. ${ }^{2}$

Seguindo o modelo barthiano, vamos levantar e classificar sem rigor, não todos os sentidos mas as formas, os códigos segundo os quais os sentidos são possíveis. Dividindo o texto em lexias, iremos ver quais são as conotações e o que revelam, desenrolando deste modo o texto em câmara lenta, seguindo sua estruturação e não necessariamente atingindo chegadas; pois o que faz o texto, como diz Barthes, é o intertextual, seu desembocar em outros textos, códigos e signos, porque a linguagem é ao mesmo tempo infinita e estruturada. Nosso texto é ao mesmo tempo suficientemente curto e simbolicamente denso, permitindo uma análise desconstrutivista.

1. Marcando o início do texto, vemos que o título - "ainda aproveitável" - sugere algo que foi posto de lado, possivelmente objetos, mas que poderia ainda ter certo uso - "Still of some use".

2. O nome da personagem principal, Foster, denota - em combinação com os termos "father", "child", etc. - "adotivo, de criação", enquanto o verbo "to foster" denota "nutrir, criar". Quando deparamos com o fato de que "Foster ajudou a ex-mulher a esvaziar o sótão da casa em que haviam morado um dia e que ela estava agora vendendo", já podemos estabelecer uma série de associações: que seu casamento estava desfeito, que a ex-mulher havia ficado com a propriedade agora à venda, que esta casa havia sido seu lar uma vez e que ele fora chamado para ajudar a esvaziar o sótão. Situado sempre na parte alta da casa e lugar onde se guarda objetos e móveis sem uso no momento, o sótão simboliza a cabeça e especialmente o inconsciente suprimido, como também o depósito da vida passada. Assim, ao venderem a casa, estariam também vendendo todo esse passado associado com os objetos guardados no sótão, que entāo precisava ser esvaziado, literal e também conotativamente.

2 CALISHER, H. and RAVENEL. S. eds. The Best American Short Stories 1981. Boston : Houghton Mifnin, 1981. p. xix-xx.

3 BARTHES, R. "Análise Textual de um Conto de Edgar Pue". In: Chabrol, C. ed. Sentiótica Narrativa e Tertual. São Paulo : Cultrix. 1977. p.36-62. 
Retornamos pois ao sobrenome Foster e vemos que não lhe foi dado nenhum nome, conotando sua relação distante e alienada com os filhos, quase como um pai adotivo. E o fato de a ex-mulher também não ter nome confirma o estranhamento que ocorreu entre ambos, pois ele se refere a ela apenas como a "ex-mulher". Percebemos então que a ação do conto já começa "in medias res", pois já existe um passado das duas personagens principais; que a narrativa se processa em terceira pessoa; e que já existe um início de um código social/cultural que aparece desfeito: o do casamento.

3. O fato de ambos "depararem" com dezenas de jogos quebrados e esquecidos já sugere algo acidental, o que é confirmado pelos adjetivos "esquecidos" e "quebrados", resgatando assim uma parte de seu passado comum, também "quebrado", desfeito e aparentemente "esquecido": a dos jogos que faziam com os filhos, competições feitas de acordo com regras preestabelecidas e decididas por habilidade, força ou sorte e projetando uma época em que todos estavam unidos e felizes, em que o código social da familia se refletia no código lúdico dos jogos. A minuciosa catalogação dos jogos sugere por sua vez: a) a grande quantidade dos mesmos, acumulados no sótão, apontando talvez para o desperdício de uma familia da classe média, comprando tantos jogos que depois foram usados apenas numa tarde de aniversário e algumas mais, e, além disso, assim que incompletos, já eram descartados e levados ao sótão sem tentativa de consertá-los, já que havia tantos; b) a quantidade de lembranças que tais jogos traziam à tona, através das palavras "natal" e "aniversário", ocasiões específicas em que a família estivera reunida e que agora eram lembradas por Foster e a ex-mulher através do ritual de retirar os jogos do sótão e da lembrança. Portanto, o código lúdico também deve ser desfeito.

4. O colorido e brilho das caixas sugere que os jogos/lembranças ainda estão vivos, no meio de roupas pequenas demais e de aparelhos sem uso - os adjetivos "usados" lembrando roupas que foram usadas pela familia e que não serviam mais e "defuntos" também conotando aparelhos sem vida, em contraposição aos jogos que conservavam sua aparência de valor, pois não haviam ainda "morrido". Eles ainda reagiam e geravam expectativas, como se o fato de terem sido usados no passado pela família houvesse deixado neles uma "vida" que não se extinguira totalmente ao irem para o sótão. Esta personificação dos jogos, com seus códigos lúdicos ainda funcionando parcialmente, remetem, por associação, ao código social da família, sugerindo assim que também nela deveria haver algo ainda vivo, funcionando, com valor.

5. A pergunta de Foster "O que vamos fazer com estes jogos?" introduz uma veia cômica, pois a decisão do que fazer com eles não justifica estar gritando, em agonia - sugerindo sua falta de controle - como se ele não soubesse 
tomar uma decisão tão simples. Por outro lado, esta vida que os jogos ainda detêm parece estar sendo percebida por Foster, ao gritar à sua familia "espalhartā", desintegrada como os jogos no sótão, enquanto subiam e desciam as escadas, imitando a corrografia de um jogo, como se eles também fossem peças no jogo da vida familiar que agora estava desfeita. A agonia de Foster é como se subitamente sua vida passada, que havia sido colocada no sótão, estivesse sendo desenterrada e algo vivo ainda permanecesse nela, como se os jogos inssem o objeto correlato das lembranças daquela época em que ainda estavam todos juntos, "jogando" a vida familiar de acordo com regras fixas, que todos obedeciam.

6. Se por uma lado a resposta do filho mais novo - grande, jovem e insensível - "Jogue-os no lixo" demostra que para ele os jogos, como o passado, não tinham mais nenhum valor, por outro lado a ex-mulher ainda é esposa o suficiente - como os jogos ainda eram suficientemente jogos para funcionar para dar resposta à pergunta de Foster - dá-los a orfanatos - sugerindo que algum liame ainda vivo existia entre ambos. Mas até os orfanatos, aos quais Foster costumava dar coisas velhas, usadas, não eram mais chamados assim, mas "lares americanos comuns", segundo Foster. Se "orfanato" tem conotação negativa, de lar para crianças sem pais, órfāos, "lares americanos comuns" também sugere que assim sāo os atuais lares americanos, em que há fillhos e pais adotivos, "foster-homes", pois há tantos lares desfeitos como refeitos com outros pais e mães, fazendo a separaçāo entre orfanatos e lares comuns desaparecer, pois não há mais limites nítidos entre um e outro, talvez uma crítica à desintegração do código social familiar norte-americano.

7. O comentário do outro filho, mais sensível, sobre as peças em falta nos jogos, justificando sua remoção ao sótão por não estarem mesmo funcionando, tornar-se ambígua, pois o termo "eles", cujo antecedente lógico é "jogos", tem como antecedente imediato "lares", o que por contigüidade nos remete ao fato de ele estar falando de lares desfeitos como os jogos e portanto jogados no sótão, nada restando dos mesmos a não ser lembranças. Novamente o código social e o lúdico são invocados, conotando sua desintegração, quando não funcionam mais.

8. Foster mostra seu esforço em querer se livrar desses jogos/lembranças ao se perguntar por que demoraram tanto em jogá-los fora, em vez de o terem feito já na ocasião. E sua resposta traz à tona talvez a razão de seu casamento também não ter dado certo, pois assim como os jogos não foram consertados na ocasião, por inércia, certos assuntos não foram discutidos no momento certo, por covardia; e certos objetos, por inércia, como também certas emoções foram colocadas no sótão, neste local esquecido do subconsciente, mesmo que ambos, objetos e emoções, ainda estivessem parcialmente funcionando. 
9. Também os filhos ainda detêm, como os brinquedos, um resquício de velha obediência, ainda "reagiam" quando "lhes era dada a oportunidade". E subitamente os brinquedos abandonados se mostram em sua "riqueza triste", em seu valor, ao tentarem lembrar com o pai aquela ocasião feliz ligada a um determinado jogo, com códigos e cores, como havia sido sua vida em família. O código metafórico, já vislumbrado anteriormente, é projetado à superfície e transparece em toda sua força, na frase "suas vidas haviam tocado uma vez nessas fichas e pedrinhas", isto é, através do "toque" os dois termos da metáfora, o código da vida familiar e o código do jogo, se sobrepõem - as personagens se identificando com as peças e sua vida familiar com o jogo que estavam jogando, enquanto percorriam, entusiasmados, os caminhos do jogo da vida. E a narrativa íntima em terceira pessoa - centrada em Foster - atinge mais um ponto de iluminação, de reconhecimento: que algo havia sido perdido daquele jogo e o dia se fora, mal permanecendo uma lembrança.

10. A voz viril do filho mais moço conotando novamente a segurança e insensibilidade com que repetia a ordem de se desfazerem dos jogos, é ainda enfatizada pela aliteração "trash'em" e toss'em" indicando a conversão daqueles jogos em "lixo" que deve ser "jogado fora".

11. Somos remetidos à primeira frase do conto, que é na realidade a razão de ser do mesmo - o ritual da faxina do sótão pela familia Foster, que agora se dá ou atirando os "itens menores" diretamente na camioneta que o filho mais moço havia emprestado para esses dias, ou carregando os itens maiores ao longo das escadas da casa, sugerindo esforço por parte da família velhos colchões, rádios, esquis e botas - assim como certos jogos também exigem esforço físico. Isto é confirmado pela lexia seguinte na qual é feita a aproximação metafórica, pois acertar os objetos pequenos dentro da camioneta se transformou numa "espécie de jogo".

12. Assim como algo permanecia "vivo" nesta familia - paradoxalmente unida ao se desfazer de objetos que faziam parte dela - também os jogos teimavam em mostrar que permaneciam vivos, quando jogados para baixo por Foster, pois subitamente pai e filhos estão jogando de novo juntos; até os jogos participavam desta nova brincadeira, mostrando sua "alma", rebelavam-se, ao estourarem, "lançando ao ar e através do gramado uma nuvem de dados, fichas, pedrinhas e cartas", provando como ainda tinham o poder de seduzir, com suas tampas mostrando crianças alegres e seus componentes plásticos derramados num canteiro de flores - como ainda tinham vida. Até uma corrida de carros flutuou suavemente como floco de neve, resgatando a lembrança de uma época passada, antes de parar num colchão manchado pelos anos.

13. Percebemos com Foster, neste momento de epifania, a causa de sua tristeza, vista "no abismo do espaço descendente": que não havia brincado o 
suficiente...com esses jogos. E, por associação, como não havia brincado o bastante com os filhos e esposa - por inércia? - ficara tarde demais, pois "agora ninguém queria jogar", a era dos jogos havia passado, assim como a era de sua vida familiar.

14. O sótão, como "inconsciente suprimido" e também como "passado", não teria sido perturbado se o casamento tivesse continuado e as feridas/ tristezas escondidas dos jogos e do casamento não estivessem sendo resolvidas. A constatação, pesarosa, de que este triste ritual de se desfazer do passado não seria necessário se tivessem se esforçado mais e evitado a separação.

15. A sugestão de que, como num casamento e num lar felizes, as lembranças da infância permanecem guardadas, aplica-se também aos jogos, igualmente com vida, apenas aguardando que alguém brinque com eles, neste retorno à infância feliz de Foster, onde havia um código lúdico o aguardando na casa da mãe, em contraposição à realidade de Foster, na qual os jogos têm de ser postos fora.

16. O diálogo entre Foster e a ex-mulher revela como ambos estão conscientes de como o tempo passara rápido e quão pouco usaram os jogos enquanto estiveram casados. E a percepção da ex-mulher de que Foster está triste demais, apesar de ter dito "nada", revela que alguma sensibilidade ainda existe, por parte dela, ainda "esposa o suficiente" para dar resposta às suas perguntas, a conversa expondo ressentimentos e saudade íntimos dos quais as personagens achavam estar imunes, como a resposta objetiva da ex-mulher "é melhor você parar agora".

17. Com o sótão vazio, com o novo jogo terminado, é a vez dele perguntar como ela suporta este vácuo. A resposta, de que era "divertido", como se fosse novamente um jogo em relação as novos inquilinos - entra o novo, sai o velho - e como se a vida se resumisse em fazer sair o não mais aproveitável e fazer entrar o novo objeto de consumo - outra familia com filhos pequenos - aponta para um novo código: o do consumismo, da troca, já vislumbrado anteriormente, mas agora concretamente assinalado pela resposta. $O$ fato de olhar para a ex-esposa e perguntar a si mesmo se suas palavras demostravam coragem ou insensibilidade permanece em aberto.

18. A resposta parece vir através do sótão tremer literalmente com a chegada de Ted, o novo namorado da ex-mulher; mas as estruturas no "sótão"de Foster também tremem - ciúme, despeito, inveja de ela estar refazendo a vida? Tremem seus sentimentos, ao ser interrompido quando conversava com a ex-mulher, como se, além dos jogos, também a casa personificasse os sentimentos da família.

O comportamento impetuoso de Ted - batendo a porta da cozinha da casa que tinha sido de Foster - provoca novamente uma reação, desta vez da 
coberta de vidro da lâmpada de querosene, que começa a vibrar. Foster se sentia preso como a vespa capturada cujo canto a lâmpada de querosene imitava, em suas vibrações. Estava mesmo na hora de ir embora, pois sentia-se também "preso" e os passos "ansiosos" da ex-mulher parecem sugerir a mesma coisa - hora de ir embora, enquanto seus joelhos "empoeirados" como os jogos e rangendo ao ficar em pé, denotando falta de exercício, parecem contrastar com a aparência do namorado, rico, grande e atlético. Assim, a casa, como os jogos, reage como ser humano, e o ser humano Foster, tem reações que lembram os jogos empoeirados mas ainda rangendo quando lhes dão corda.

19. Outra lembrança do passado vem à tona, ao deparar com a prateleira de pinho que havia construído cuidadosamente e a perfeição da madeira, projetando como, numa determinada época, a vida familiar deles também havia sido tão sólida, perfeita e bela.

20. O contraste entre os quartos vazios e mortos da casa e a cozinha, cheia de "calor e vida" e onde a ex-famnlia se encontrava reunida naquele momento, atesta mais uma vez que a casa tivera alma que ainda irradiava daquele lugar que costumava ser o centro do calor humano, onde se preparavam as refeições, mas onde agora se encontra um fogão desligado. Por que "destoantemente"cheia de vida? Porque Foster não queria mais recomeçar o jogo da vida familiar, que imaginava estar desfeito? Ou porque lá estava a presença perturbadora de Ted? O filho mais velho lhe oferece uma cerveja e sua namorada the sorri, parecendo a Foster que ele era benvindo à cozinha. Mesmo assim, mantém-se determinado a ir embora, não quer mais jogar e recusa a cerveja.

21. O aperto de mãos com o rival, já usual, apenas confirma a superficialidade das convenções sociais, pois já tivemos indicações de que sua presença irritava Foster. Isto é confirmado pela lexia seguinte, em que o "rival" é descrito como um brutamontes com ondas artificiais no cabelo, emprego pacato e vindo de outro lar desfeito. Esta descrição é tão negativa quanto a de sua chegada e o fato de Foster não poder encará-lo confirma não simpatizar com Ted. Mesmo assim, é obrigado a manter diálogo com ele, que por sua vez também soa artificial, confirmando a ironia da situação, pois é o atual namorado que elogia a atuação de Foster em esvaziar a própria casa.

22. A resposta de Foster, minimizando sua atuação ao dizer "não ajudei muito" ("I wasn't much use"), nos remete ao título - "Still of Some Use" mostrando que ele achava ter perdido sua utilidade como chefe de família. Esta constatação o atordoou, de que havia comprado tanta coisa para a família de que não se lembrava mais, desenterrando assim mais uma vez o passado.

23. A ex-mulher, ao aceitar a cerveja do filho e que Foster havia recusado, parece estar provocando o ex-marido, pois este reage tirando a lata 
de sua boca e tomando um grande gole, após ter "implorado": "dê-me um golinho". Parece que percebeu que o jogo das aparências continuava e que tinha de entrar nele, mesmo que atrasado.

24. Assim como ele parecia querer um carinho da ex-mulher, ao beber de olhos fechados, quando os reabre ela está recebendo um "gesto protetor" do namorado ao limpar seu queixo, evidenciando novamente que ela não é mais sua, que havia outra pessoa protegendo a "Sra. Foster". E a visão que Foster tem de ambos é novamente colorida pela subjetividade da narrativa íntima em terceira pessoa: ela apresenta um rosto pequeno, amuado, frágil e murcho, como se tivesse perdido algo de sua felicidade, enquanto a roupa de Ted é descrita como tendo uma "perfeição cômica", pois acentuava sua idade. É assim que Foster acaba vendo ambos, como um casal de meia idade, comovedor. Novamente decide sair, pois o novo "lar" que ambos formavam excluía sua presença.

25. O diálogo, que se inicia formal, sofre de repente uma reviravolta, quando a ex-mulher the pede para falar com o filho mais moço, Tommy, pois ela percebera o quanto ele estava sofrendo com a faxina do sótão, apesar de sua aparência viril. Foster, por sua vez, qual vespa presa, acha que ela ainda estava preparando outra armadilha para não deixá-lo sair imediatamente, revelando mais uma vez uma fração do passado comum de ambos. Mostra, por parte dela, a sensibilidade que Foster não lhe queria atribuir ou que ela não queria mostrar, como o filho.

26. Nova visão negativa e cômica do atual pretendente da ex-mulher, cujo relógio, volumoso e chamativo, revelava mais uma vez seu poder aquisitivo e sua esportividade.

27. O diálogo entre Ted e o irmão mais velho, comentando o fato de Tommy ficar devaneando no sótão em vez de ir ao depósito de lixo levar as coisas, confirma a sensibilidade do mesmo, já indicada pela mãe, e ao mesmo tempo a insensibilidade de Ted, para quem as "coisas velhas". não tinham significação.

28. Nowo jogo se inicia com Tommy e Foster juntando o lixo que havia caído fora da camioneta, como se estivessem retornando aos tempos antigos. Mas as dezenas de fichas e dados espalhados na grama tinham seu código perdido e Foster não consegue se lembrar de que jogos eram. Mas Tommy se lembra sem hesitação a que jogo as peças pertenciam e até de um caça-níqueis que pertencia a um jogo chamado "Idiotas do Jogo", numa alusão irônica a eles próprios.

29. A mesma luz de antigamente brilha de novo em seus olhos, quando jogava com a familia, o que o faz agora convidar o pai a terminar o ritual e 
acompanhá-lo ao depósito de lixo. O fato de ainda estar crescendo, apesar de já encorpado, confirma sua adolescência, em relação ao pai.

30. O convite para "entrar no jogo" é novamente recusado por Foster, que percebe, pelo fato de estar numa casa que não é mais dele, estar no "quadrado errado" de um tabuleiro de xadrez, uma peça que precisava ser removida; e assim como a ex-mulher já levava nova vida, ele também tinha uma vida nova a levar, pois perdera a partida e tinha de entregar o campo ao adversário.

31. Mais um jogo é lembrado: quando ensinara xadrez ao filho, este mesmo Tommy que agora estava jogando com o pai o ritual da remoção final das coisas da casa. E a tristeza que Tommy demonstrava ao perder para o pai o rei capturado no jogo de xadrez e que fazia o pai interromper as lições, projeta mais uma vez a grande metáfora que percorre o conto - o jogo da vida familiar, interrompido no passado literalmente no jogo de xadrez e metaforicamente no jogo de casamento desfeito.

32. As últimas fichas, que Tommy reconhecera, são por sua vez jogadas na camioneta e, com a vida que ainda detém, retiniram antes de repousarem sobre o metal, em sua última tentativa de provarem que ainda funcionam, quando acionadas, que ainda têm alma, ecoando como nos velhos tempos. E é este som prolongado que faz o pai perguntar ao filho, lembrando-se provavelmente de sua tristeza quando perdia no jogo de xadrez: "Isto o deprime?" Sua resposta, primeiro negativa, depois concedendo estar triste, revela ter sido afetado pelo som das fichas que exprimiam terem vida, quando brincavam com elas.

33. A sensibilidade do rapaz faz Foster adquirir autoconfiança, estimulando-o a irem ao depósito e lembrando-lhe como ele próprio adorava ir lá, com toda "aquela velha felicidade acumulada", em que o código metafórico atinge o auge, na identificação jogos-felicidade familiar.

34. A afirmação do rapaz de que as coisas mudaram desde que Foster fora embora é ambígua, pois apesar de se referir ao depósito de lixo, com novos regulamentos, remete imediatamente ao fato de Foster ter deixado o lar, fazendo "as coisas" - a vida familiar - mudarem. O fato de Tommy se assustar com a zeladora ter ralhado com ele por colocar o lixo no lugar errado parece fazer Foster hesitar e agora é a vez de Tommy incentivar o pai a ir até lá, dizendo "vai levar apenas vinte minutos".

35. A descrição de Tommy, com vestígios de nenê prestes a chorar ao se sentir frustrado e ante a hesitação do pai, confirma sua sensibilidade e reanima Foster a ir com ele e protegê-lo - enormemente aliviado, ao perceber que Tommy, adolescente, ainda precisava da proteção do pai e que ele "ainda era aproveitável" e podia ser útil ao filho. A aproximação e distância do diálogo 
final projetam mais uma vez a coreografia de um jogo em que o pai ajuda ao filho mais moço a jogar, ao protegê-lo dos "inimigos"..

Assim, observamos a narrativa como processo de autoconstrução e, através do progressivo desenrolar do texto, chegamos aos códigos principais do conto:

a) o código cultural/social que é desintegrado - a família dispersa, que se encontra para dispor dos objetos do sótão da casa em que uma vez haviam morado: b) o código comunicativo ou fático; c) o código das ações: jogar fora, fazer faxina no sótão; d) o código simbólico/metafórico ou lúdico, em que temos, através do conto, a formação lenta e gradual de um desvio, de uma transgressão, em que percebemos que assim como os jogos não eram mais usados, mais ainda detinham vida dentro de si, também a familia apesar de dispersa, ainda tinha laços afetivos aproximando marido e mulher, e os filhos ao pai, mesmo que tentassem mascarar esses laços. No final o pai, apesar de derrotado - pois está divorciado e a ex-mulher tem novo namorado - o pai ainda é "aproveitável", ainda pode ser útil, ao acompanhar o filho ao depósito de lixo e poder protegê-lo contra terceiros e esta revelação final o redime daquela . constatação anterior de que ele havia falhado no passado, ao não ter brincado o suficiente com os filhos e que agora era tarde demais.

Assim, o código simbólico colore e contamina o código social/cultural do conto, no momento em que a ação da familia de esvaziar o sótão é respondida com a reação dos jogos, que ainda têm alguma utilidade e no momento em que, através do diálogo e das ações de Foster, também demonstram que algo permaneceu do casamento desfeito. Com esta contaminação do real pelo metafórico percebemos quanto o conto está dentro da vertente lírica da narrativa, através da metáfora matriz personagem/jogo - ambos ainda "úteis", apesar da fragmentação dos códigos social/cultural e lúdico ao qual pertencem, personagens e peças de jogo.

\section{RESUMO}

Este trabalho apresenta uma keitura desconstrutivista do conto "Ainda Aproveitável" de John Updike a fim de demonstrar como o conto se insere na vertente lírica da narrativa através da metáfora-matriz personagem/jogo que percorre o texto.

Palavras-chave: Conto dos Anos 80, Ficção norte-americana, John Updike. 


\section{SUMMARY}

This work presents a deconstructionist reading of John Updike's short story "Still of Some Use" in order to demonstrate how the tale is inserted in the lyric tradition of the narrative by way of the matrix-metaphor protagonist/game which pervades the text.

\section{REFERÊNCIAS BIBLIOGRÁFICAS}

BALDESHWILER, E. "The Lyric Short Story: The sketch of a history". In: Short Story Theories. Ed. Charles E. May. Ohio University Press, 1976.

BARTHES, R. "Análise Textual de um conto de Edgar Poe". In: Chabrol, C. ed. Semiótica Narrativa e Textual. São Paulo : Cultrix, 1977.

CALISHER, H.; RAVENEL, S. eds. The Best American Short Stories 1981. Boston : Houghton Mifflin, 1981. 